\title{
Effect of an Educational program about Attention Deficit Hyper Activity Disorder on Teachers Knowledge and skills in primary schools
}

Marwa abd elfatah Ahmmed zewiel, Clinical Demonstrator of Psychiatric and Mental Health Nursing

Faculty of Nursing, Tanta University

Mervat Hosney,shalaby, assistant professor of Psychiatric and Mental Health Nursing,

Faculty of Nursing, Tanta University

Zebeda Abd El Gawad Elsherif, lecturer of Psychiatric and Mental Health Nursing,

Faculty of Nursing, Tanta University

\begin{abstract}
Attention deficit hyperactivity disorder is one of the most prevalent behavioral disorders affecting children and adolescent worldwide. It causes a grave problem to child, teacher and family. The study aimed to evaluate the effect of educational program about Attention Deficit Hyper Activity Disorder on primary schools teacher's knowledge and skill. This study was conducted at two governmental primary schools at Elgharbia Governorates (one urban and another rural), the subject of the study were 50 primary school teachers. This study followed a quasi-experimental design. Two tools were used for the data collection, Tool 1 include : part a: Socio-demographic data, : part b: Knowledge of Attention Deficit hyper activity Disorders Scale (KADDS) to assess teachers' knowledge about ADHD, Tool 2 include : Teacher Intervention Survey to determine teachers skills regarding interventions that a teacher can use with students with a DHD.. The study program included 4 sessions for six months. The designed educational program helped teachers through providing efficient knowledge and skill regarding ADHD. The results revealed that the designed program had an effective impact on teachers' knowledge and skill regarding ADHD as there was a statistically significant difference between total score of knowledge and skill before implementing the program, immediately after and at follow up .The study concluded that educational program about ADHD can improve level of teacher's knowledge and skills about ADHD. According to these results, the researcher recommended that teachers should be offered in-service training in ADHD, as well as behavioral management and academic interventions (curriculum adaptations) regarding ADHD.
\end{abstract}

Keywords; Attention deficit hyperactivity disorder, Teachers, knowledge

\section{Introduction}

The global burden of disease indicates that by the year 2020, childhood neuropsychiatric disorders will increase by more than $50 \%$ internationally to become one of the five most common causes of 
morbidity and disability among children. the attention deficit hyper activity disorder will be one of most widely studied of this disorder among children and adolescents. ${ }^{(1)}$

Attention deficit hyper activity disorder is characterized by a persistent pattern of inattention, hyperactivity and impulsivity that is more frequently displayed and more severe than is typically seen in individuals at a comparable level of development and these symptoms must present in more than one setting ${ }^{(1,2)}$

Attention deficit hyper activity disorder affect $8-12 \%$ of elementary school children (worldwide), and affects $7.48 \%$ in (Egypt) these variable incidence of attention deficit hyper activity disorder is depending on the diagnostic criteria and assessment tool ${ }^{(3,4)}$

Attention deficit hyper activity disorder cause grave problems for suffers and those around them as they have a variety of school-related problem including difficulty in paying attention, following directions, staying seated, completing listening, assignments and also exhibit social problems including poor relations additionally these problems are often accompanied by other associated Problems as low self-esteem that may further affect the academic performance of these students and also social problem as anti-social behavior, have trouble getting along with others, and are often less liked by their peers. ${ }^{(5,6)}$

Attention deficit hyper activity disorder cause grave problems for family as more time and attention needed to deal with a child with attention deficit hyper activity disorder can change internal family relationships and create conflicts with parents and siblings ${ }^{(6)}$

Child with attention deficit hyper activity disorder liable to high comorbidity rate with other disorders, as anxiety disorder, major depression, oppositional defiant disorder and conduct disorder are $25 \%, 35 \%$ and $20-56 \%$, respectively ${ }^{(6,7)}$

Attention deficit hyper activity disorder has breached the boundaries of academic research and study and become a social phenomenon, as any child who shows a certain degree of activity, who does not remain seated and quiet for hours and does not instantly obey each and every instruction he or she receives that is immediately suspected of having attention deficit hyper activity disorder. ${ }^{(7,8)}$

Teachers play an important role due to long contact with student in school than family, so they are one of the most suitable groups to receive information and training regard attention deficit hyper activity disorder. As teacher with more knowledge about attention deficit hyper activity disorder has a more favorable conduct and attitudes towards students with this disorder.

A significant percentage of teachers have false ideas or gaps in their knowledge of attention deficit hyper activity disorder, which causes them to behave inappropriately in the classroom

In this regard it has been observed that specific training of teachers in the field as give student positive and negative verbal feedback, as well as nonverbal feedback such as nods, frowns, smiles, pats of approval, taking away privileges, tokens, or points, for inappropriate behavior, restricting the child's access to positive reinforcement such as placing the child in the corner of the room on a chair have positive consequences for these children ${ }^{(11-13)}$

In working effectively with students diagnosed with attention deficit hyper activity disorder many factors have to be considered, teachers need to be knowledgeable not only about the etiology, diagnosis, and prognosis of the disorder, they also need to know how to implement educational 
interventions that have been shown to have positive outcomes for students with attention deficit hyper activity disorder, Therefore, investigating ways of helping teachers to teach students with attention deficit hyper activity disorder is extremely important. ${ }^{(14,15)}$

The most effective therapeutic approach for childhood attention deficit hyper activity disorder is multimodal treatment which consist of multiple elements including stimulant medication, parental training, teacher's education by identifying teachers' knowledge about attention deficit hyper activity disorder as it provide data regarding what kinds of information teachers are lacking in this area and help them to implement various educational interventions (e.g., token economy, teacher attention ,response cost, time out $)^{\cdot(16,17)}$

\section{The aim of this study is to:}

Evaluate the effect of an educational program about Attention Deficit Hyper Activity Disorder on teachers' knowledge and skills in primary schools

\section{Research hypothesis:}

Educational program increase the Primary school teachers' knowledge and skills when deal with Attention Deficit Hyper Activity Disorder.

\section{Materials and Method \\ Materials}

Research design:-A quasi-experimental design was used for this study.

Setting: According to cluster random sampling, the study was conducted at two governmental primary schools at Elgharbia Governorates (one urban and another rural) Subjects: According to (Epi info program) the target population of this study will consist of 50 teachers from primary school at Elgharbia governorates who were fulfilling the following inclusion criteria:

- Age less than 55 years.

- Both sexes.

- Willing and agree to participate in the study.

\section{Tools of the study:}

The data of this study was collected by using the following tools:

Tool I: Knowledge of Attention Deficit hyper activity Disorders Scale (KADDS).

Part a; Socio Demographic data: It was developed by researcher to assess the socio demographic data about teachers, it was included 5 demographic questions (age, gender, highest degree attained, and numbers of total years of teaching. Grade level (he, she) currently teach

Part b: Knowledge of Attention Deficit hyper activity Disorders Scale (KADDS). It was developed by (Garque N, Tarraga L, Miranda L 2007) ${ }^{(18)}$ and modified by researcher after review of related literature It was consist of 30 items designed to assess teachers' knowledge regarding symptoms, diagnosis, the treatment, and general information about the nature, causes, and outcome of attention deficit hyper activity disorder. Each item was answered as "True," "False," or "Don't Know." Correct answers are scored as one point; 
incorrect, don't know, and missing answers are scored as zero points. Each teacher can receive score ranging from 0 to 30 grades. Evaluation of this questionnaire will be as follow:

$<50 \%=$ Poor

$50-75 \%=$ Average

$>75 \%=$ Good

Tool II: Teacher Intervention Survey:It was modified by researcher from a version of a teacher intervention survey that developed by Matlock, (1999) ${ }^{(19)}$, it will be used to determine teachers skill regarding interventions for response of students with attention deficit hyper activity disorder. Each item is scored on a 5-point Likert scale ranging from 1 (very low) to 5 (very high). The minimum score is 12 and maximum score is 60. This include "how knowledge they have regarding ADHD intervention," "how effective they perceive them," and "how willing they would be able to implement various interventions in their classrooms for stude with attention deficit hyper activity disorder.

It consists of four sections.

Section 1 contains three items that measure teachers' attention in giving students positive and negative verbal feedback, as well as nonverbal feedback.

Section 2 contains three items that measure teachers' knowledge regarding the intervention (response cost taking away privileges, tokens, or Points for inappropriate behavior) and ability to implement.

Section 3 contains three items that measure teachers' knowledge regarding this intervention the time out from positive reinforcement and the ability to implement it.

Section 4 contains three items that measure teacher knowledge regarding this intervention (structure) and the ability to implement it by providing organization in the classroom such as posting rules, providing students with daily schedules.

Evaluation of this questionnaire will be as follow: The total score is the summation of the total score of the questionnaire 12 questions, the minimum score should be 12 and the maximum score 60 , the total score for each study participants was divided by the maximum score and multiplied by 100 to percentage of total of each participants. The percentage of total score was categorized by the followings:

$<50 \%=$ Poor

$50-75 \%=$ Average

$>75 \%=$

Good

\section{Method}

-An official approval was obtained from the identified school to collect the study data.

-Ethical consideration:

- Written consent was obtained from teachers after explanation of the aim of the study.

- Privacy and confidentiality were assured.

- Teacher's rights to withdraw from the study at any phase were respected. 
- Tools (I part b) and tool (II) was modified by the researcher by adding score through statistics expert.

-All tools was translated into Arabic by the researcher, and tested for their translation and content validity by five experts in the psychiatric field.

-Internal consistency of the study tools (I part b) and tool (II) was done by means of Cronbach's Alpha coefficient which yielded values of $r=0.9421-r=0.9325$ respectively.

-Tool (I part b) and tool (II) was applied three times, the first one pre-test and the second post-test immediately after application of the program and third after one month from the end of program.

-A pilot study was conducted on 5 teachers out of the proposed sample after taking their approval to test the feasibility and applicability of the study tools, and determine obstacles that may be encountered during period of data collection, after its implementation and according to result some statement of tool II needed rewording and re tested.

\title{
The actual study carried out in four phase:
}

\author{
a-Assessment phase:
}

-The researcher reviewed all teachers' record in order to select those who meet the inclusion criteria. And asked to participate in the study after explaining the aim of the study.

-The selected teachers were undergoing a pre-test using the two tools in the presence of the researcher for necessary clarification.

-Each interview lasted from 30-45 minutes according to the teacher's free time (break).

Before the beginning of the program, the researcher fixed a meeting time with the participants, on Saturday, Thursday (every other week). This assessment phase lasted for 4 weeks.

\section{b-Planning phase:}

-The educational program was developed by the researcher based on data from the assessment phase and literature review.

-Expected Outcomes:

-Improvement Primary school teacher's Knowledge and skill regard Attention Deficit Hyper Activity Disorder.

-Primary school of teachers becomes able to deal with child who has ADHD effectively.

*The researcher prepared videos, pictures and power point presentations to be used in the educational program.

*Colored booklets were developed to be distributed to every teacher for enforcement.

*The researcher modified number of program sessions based on the assessment phase to be five sessions instead of four sessions. 


\section{c-Implementation phase:}

The educational program was implemented by the researcher and these sessions aimed to increase teacher's knowledge about (attention deficit hyperactivity disorder). Each educational session took about 2 hours for 2 days. The program was implemented on a small group basis. Each sub group was encompassing 5 teachers attending a total of 4 sessions. These sessions were being scheduled as 1 sessions per week for duration of about 4 weeks (one session lasted for 2 days). Total duration of session was 8 hours for each school as it was conducted in two schools include the following sessions;

Session 1: This session was include Introduction, definition, history of attention deficit hyper activity disorder, causes (genetics causes, societal causes and environmental causes) of attention deficit hyper activity disorder to increase teacher knowledge about attention deficit hyper activity disorder.

First day the researcher divided this session, first half hour was introduction about ADHD, definition, history of attention deficit hyper activity disorder, supported by power point, and then gave teachers break for 10 minutes after that researcher give teachers 10 minutes to ask any question, and then researcher give teachers 20 minutes to give situation that they meet with such children.

On the second days a researcher divided this session, first half hour was for discussing causes (genetics causes, societal causes and environmental causes) of attention deficit hyper activity disorders with teachers. And then gave teachers a break for 10 minutes. After that researcher gave teachers 10 minutes to ask any question, and then give teachers 20 minutes to summarize all the outlines of the two days.

Session 2: This session covered the topic Epidemiology, path physiology of attention deficit hyper activity disorders, signs \& symptoms (diagnosis) according to DSM5 criteria of attention deficit hyper activity disorder.

The researcher divided this session, as follow; first 30 minutes was explanation for Epidemiology, path physiology of attention deficit hyper activity disorders, supported by power point presentations, pictures and then gave teachers break for 10 minutes, after that researcher give teachers 20 minutes to ask any question and make free discussion.

While second days a researcher divided this session, first half hour was discuss signs \& symptoms (diagnosis) according to DSM5 criteria of attention deficit hyper activity disorder with teachers. then gave teachers a break for 10 minutes, after that the researcher gave teachers 10 minutes to discuss case study with them that include all signs \& symptoms of attention deficit hyper activity disorder. And then the researchers gave teachers 10 minutes to summarize all the outlines of the two days. 
Session 3: This session covered the topic, prognosis and impact of attention deficit hyper activity disorders on the suffered children and their family, teachers, learning outcomes. The researcher divided this session, first 30 minutes was explanation for prognosis and impact of attention deficit hyper activity disorder on the suffered children and their family, supported by power point shows, pictures and then gave teachers break for 10 minutes, after that researcher give teachers 20 minutes to ask any question.

While second days a researcher divided this session, first half hour was discussion impact of attention deficit hyper activity disorders on teacher and learning out come with teachers then gave teachers break for 10 minutes. After that the researcher gave teachers 10 minutes to make free discussion .And then gave teachers 10 minutes to summarize all the outlines of the two days.

Session 4:This session covered the topic, method of management (How to deal with attention deficit hyper activity disorders), and barriers of implementation. The researcher divided this session, as follow the first 30 minutes were for the explanation for method of management (How to deal with attention deficit hyper activity disorders), supported by power point shows, pictures and role plays. Then gave teachers a break for 10 minutes, after that the researcher gave teachers 20 minutes to ask any question.

While one the second days a researcher divided this session, as the follow ,the first half hour was discussing barriers of implementation that face teachers then gave teachers a break for 10 minutes. After that, the researcher gave teachers 10 minutes to discuss case study about ADHD. And then gave teachers 10 minutes to summarize all the outlines of the two days.

-The program was presented through a discussion between the researcher and the teachers. Visual aids, and handouts was used whenever needed to supplement discussions, and guidance booklet were distributed to the teachers during the study.

\section{d-Evaluation Phase:}

The evaluation of the implemented program was done by:

-Reapplying Knowledge of Attention Deficit hyper activity Disorders -Scale (KADDS) and Teacher Intervention Survey was being done as follows:

- Immediately after implementation of the program (post test 1).

- One month later after program implementation (post test 2).

- Data were collected over a period of 6 month starting from October 2014 to Mars 2015.

\section{Statistical Analysis}

The collected data were organized, tabulated and statistically analyzed using SPSS version 19 (Statistical Package for Social Studies) created by IBM, Illinois, Chicago, USA. For categorical variable the number and percentage were calculated and differences between subcategories were tested by chi square (X2). When chi square was not appropriate Monte Carlo exact testes were used. The relations between two variables were tested by Pearson's correlation coefficient. The level of significant was adopted at $\mathrm{p}<0.05$. 


\section{Results}

Table 1 ; presents Socio-demographic and clinical characteristics of the studied teachers. The results revealed that the most of teachers $(92.0 \%)$ were married with a mean age of $(39.00 \pm 9.28$ years). Regarding their residence, half of teachers (50\%) lived in rural areas. In relation to teaching classes of the teachers, more than half of teachers (64.0\%) teaching the Fourth to Sixth classes. Regarding to Post graduate educational training in education most of them (88.0\%) had Post graduate educational training.

Table (2) show distribution of studied teachers in relation to their experience in giving students verbal and non verbal, positive and negative reactions (intervention).The results revealed that there was statistically significant relation between knowledge, skills and opinion of the teachers regarding intervention before the educational program and immediately after the educational program and after one month of implementation of the educational program as $\left(\mathrm{P}=0.001^{*}\right)$.

Regarding knowledge that teachers have about this intervention (question 1) (22\%) of the studied teachers have low knowledge regarding this intervention before the implementation of the educational program but immediately after the implementation of the program about $(38 \%)$ of studied teachers have high knowledge regarding this intervention.

In relation to skills that teachers have regarding this intervention (question 2) the results revealed that about $(22 \%)$ of the studied teachers have low skill before the educational program. While after one month from the implementation of the educational program, $(86 \%)$ of the them have high skill regarding this intervention .Regarding the degree of effectiveness that the teacher think about these intervention (question 3), the results revealed that about (18\%) of the studied teachers have low knowledge about it before the educational program, while after one month from the implementation of the educational program these percentage become decreased to $(0.0 \%)$, and teachers who have high knowledge became increased to (66.0\%).

Table (3) show distribution of studied teachers in relation to their experience regarding response cost (intervention). The results revealed that there was statistically significant relation between knowledge, skills and opinion that teachers have regarding to response cost (intervention) before the educational program and immediately after the educational program and after one month of implementation of the educational program as $(\mathrm{P}=0.001 *)$.

Regarding knowledge that teachers have about this intervention (question 1),(24\%) of the studied teachers have a low knowledge regarding this intervention before the implementation of the educational program but after one month the implementation of the program these percentage of the studied teachers decreased to $(0.0 \%)$, and the teachers have high knowledge became $(84.0 \%)$. In relation to skills that the teachers have regarding this intervention (question 2) the results revealed that about (20\%) of the studied teachers have low skill about this intervention before the educational program. While after one month from the implementation of the educational program $(92 \%)$ of them studied teachers have high skill regarding this intervention. 
Regarding degree of effectiveness that teacher think about these intervention (question 3) ,the results revealed that $(20 \%)$ of the studied teachers have a low knowledge about it before the educational program. While after one month from the implementation of the educational program, $(88 \%)$ of studied teachers have a high skill regarding this intervention.

Table (4) show distribution of studied teachers in relation to their experience regarding providing organization at classroom (intervention). The results revealed that there was statistically significant relation between knowledge, skills and opinion of the teachers regarding to these intervention before the educational program and immediately after the implementation and after one month as $(\mathrm{P}=0.001 *)$.

Regarding the knowledge that the teachers have about this intervention (question 1),(16\%) of the studied teachers have low knowledge regarding this intervention before the implementation of educational program but after the implementation of the program these percentage of the studied teachers decent to $(2.0 \%)$,and teachers who have a high knowledge became $(86 \%)$, In relation to the skills that the teachers have regarding this intervention (question 2) the results revealed that about $(50 \%)$ of them have a high skill about this intervention before the educational program. While after one month from the implementation of the educational program this percentage become $(84 \%)$.

Regarding the degree of effectiveness that the teachers think about this intervention (question 3 ), the results revealed that (14\%) of the studied teachers have a low knowledge about it before the educational program, while after one month from the implementation of the educational program $(86 \%)$ of them have a high skill regarding this intervention.

Table (5) show distribution of studied teachers in relation to their experience regarding time out from positive reinforcement (intervention).The results revealed that there was statistically significant relation between knowledge, skills and attitude that teachers have regarding to these intervention before the educational program and immediately after the educational program and after one month of implementation of the educational program as $\left(\mathrm{P}=0.001^{*}\right)$.

Regarding the knowledge that the teachers have regarding this intervention (question 1), (40\%) of the studied teachers have low knowledge regarding this intervention before the implementation of the educational program but after the implementation of the program these percentage of decreased to $(4.0 \%)$, and the teachers have a high knowledge became $(68 \%)$.

In relation to the skills that the teachers have regarding this intervention (question 2), the results revealed that about (30\%) of the studied teachers have a high skill about this intervention before the educational program, while after one month from the implementation of the educational program this percentage became $(74 \%)$. As regards the degree of effectiveness that the teachers think about this intervention (question 3) the results revealed that (24\%) of the studied teachers have a high knowledge about it before the educational program, while after one month from the implementation of the educational program these percentage become $(80 \%)$ of they have a high skill regarding this intervention. 
Table (6): Correlation between total knowledge and experience score in relation to age in years. The results revealed that there was statistically significant relationship between total knowledge in relation to age in years, in which $\mathrm{r}=0362$ and $\mathrm{P}=0.011$ and experience score in which $\mathrm{r}=0295$ and $\mathrm{P}$ $=0.044$

Table (7); Shows correlation between knowledge and experience total scores before, immediately after and after one month from implementation of educational program. The results revealed that there was statistically significant relation between total score of knowledge immediately after implementation of educational program in which $r=0.362$ and $\mathrm{P}=0.001 *$. Also there was statistically significant relation between total score of knowledge after one month from implementation of educational program in which $\mathrm{r}=0.423$ and $\mathrm{P}=0.002 *$.

Figure (1) Shows Distribution of studied teachers in relation to total knowledge score in dealing with children with attentive hyperactivity disorder. The results revealed that there is statistically significant relation between total knowledge score pre, immediate and after the educational program in dealing with children with attentive hyperactivity disorder. The results showed that $22.0 \%$ of studied teachers had good knowledge regarding attentive hyperactivity disorder before the educational program. While it increased to $96.0 \%$ in the same category immediately after the educational program implementation and then become $98.0 \%$ of studied teachers in the same category one month after the educational program implementation

Figure (2): Shows Distribution of studied teachers in relation to total experience score in dealing with children with attentive hyperactivity disorder. The results revealed that there is statistically significant relation between total experience score pre, immediate and after the educational program in dealing with children with attentive hyperactivity disorder. The results showed that $12.0 \%$ of studied teachers had good experience regarding attentive hyperactivity disorder before the educational program. While it increased to $50.0 \%$ in the same category immediately after the educational program implementation and then become $74.0 \%$ of studied teachers in the same category one month after the educational program implementation.

Figure (3); Shows relation between total knowledge score and residence. The results showed that $12 \%$ of studied teachers who live in urban area had poor knowledge regarding attentive hyperactivity disorder. And only $8 \%$ of studied teachers who live in rural area had poor knowledge, While $24 \%$ of studied teachers who live rural area had good knowledge regarding attentive hyperactivity disorder, while $10 \%$ of studied teachers who live in urban area had good knowledge. And there was no significant relationship between urban and rural teachers in their knowledge regarding attentive hyperactivity disorder.

Figure (4); Shows relation between total practice experience score and residence. The results showed that $20 \%$ of studied teachers who live in rural area had poor experience more than teachers who live in urban area who had $12 \%$ poor experience. While the same percent $12 \%$ of teachers who live in rural and urban area had good experience about attentive hyperactivity disorder. And there 
was no significant relationship between urban and rural teachers in their experience regarding attentive hyperactivity disorder

Table (1): Socio-demographic characteristics of studied teachers

\begin{tabular}{|c|c|c|}
\hline Socio-demographic characteristics & $\begin{array}{c}\text { Number } \\
(\mathrm{N}=50)\end{array}$ & $\%$ \\
\hline \multicolumn{3}{|l|}{ Age in years: } \\
\hline $25-$ & 13 & 26.0 \\
\hline $35-$ & 14 & 28.0 \\
\hline $45-55$ & 23 & 46.0 \\
\hline Range & \multirow{2}{*}{\multicolumn{2}{|c|}{$\begin{array}{c}25-55 \\
39.00 \pm 9.28\end{array}$}} \\
\hline Mean \pm SD & & \\
\hline \multicolumn{3}{|l|}{ Marital status: } \\
\hline Single & 4 & 8.0 \\
\hline Married & 46 & 92.0 \\
\hline \multicolumn{3}{|l|}{ Residence: } \\
\hline Urban & 25 & 50.0 \\
\hline Rural & 25 & 50.0 \\
\hline \multicolumn{3}{|l|}{ Teaching classes: } \\
\hline First to third & 10 & 20.0 \\
\hline Fourth to sixth & 32 & 64.0 \\
\hline All class & 8 & 16.0 \\
\hline Post graduate training in education & 44 & 88.0 \\
\hline
\end{tabular}


Table (2): Distribution of studied teachers in relation to their experience in giving students verbal and non verbal response, positive and negative reaction $(\mathrm{n}=50)$

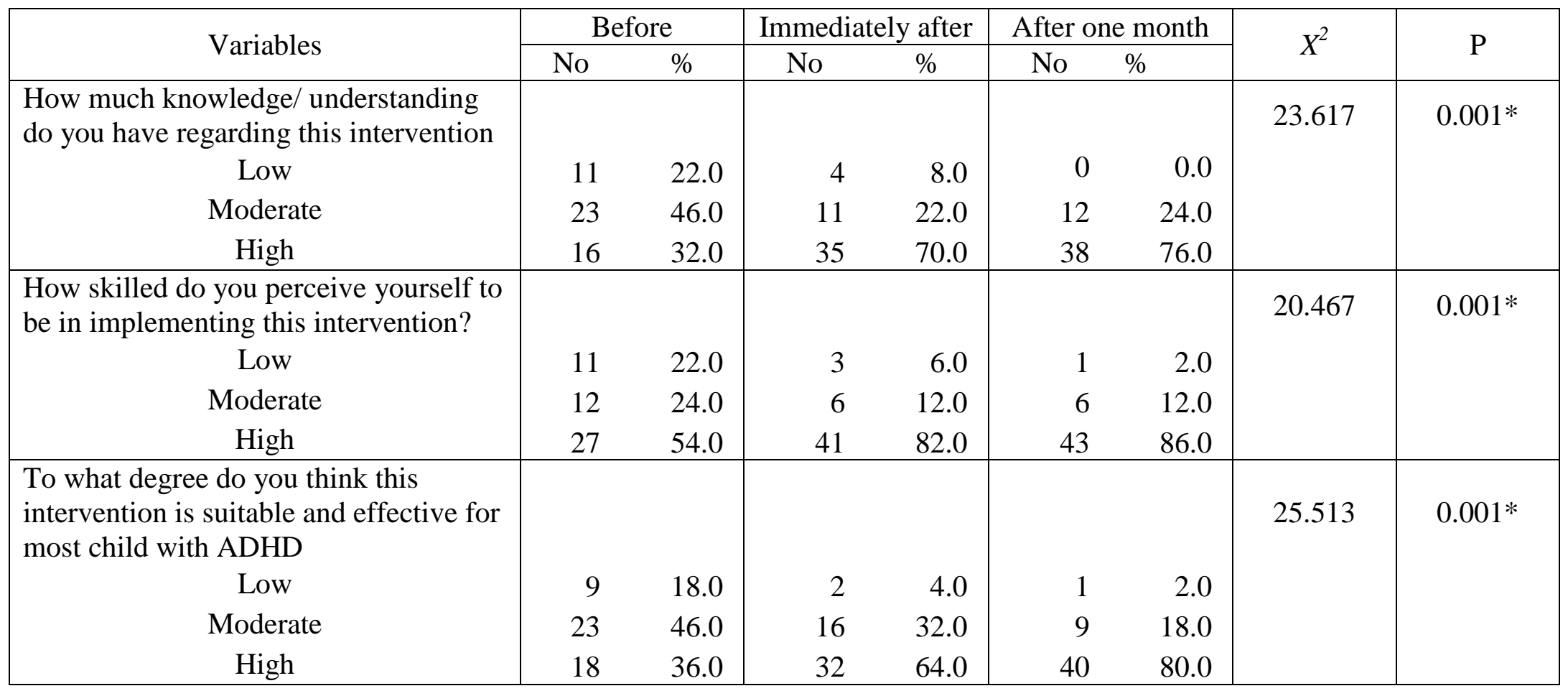

*Significant 
Table (3): Distribution of studied teachers in relation to their experience regarding response cost $(n=50)$

\begin{tabular}{|c|c|c|c|c|c|c|c|c|}
\hline \multirow{2}{*}{ Variables } & \multicolumn{2}{|c|}{ Before } & \multicolumn{2}{|c|}{$\begin{array}{c}\text { Immediately } \\
\text { after }\end{array}$} & \multicolumn{2}{|c|}{ After one month } & \multirow{2}{*}{$X^{2}$} & \multirow{2}{*}{$\mathrm{P}$} \\
\hline & No & $\%$ & No & $\%$ & No & $\%$ & & \\
\hline $\begin{array}{l}\text { How much knowledge/ understanding } \\
\text { do you have regarding this intervention }\end{array}$ & & & & & & & 32.610 & $0.001 *$ \\
\hline Low & 12 & 24.0 & 2 & 4.0 & 0 & 0.0 & & \\
\hline Moderate & 22 & 44.0 & 12 & 24.0 & 8 & 16.0 & & \\
\hline High & 16 & 32.0 & 36 & 72.0 & 42 & 84.0 & & \\
\hline $\begin{array}{l}\text { How skilled do you perceive yourself to } \\
\text { be in implementing this intervention? }\end{array}$ & & & & & & & 35.436 & $0.001^{*}$ \\
\hline Low & 10 & 20.0 & 1 & 2.0 & 1 & 2.0 & & \\
\hline Moderate & 22 & 44.0 & 16 & 32.0 & 3 & 6.0 & & \\
\hline High & 18 & 36.0 & 33 & 66.0 & 46 & 92.0 & & \\
\hline $\begin{array}{l}\text { To what degree do you think this } \\
\text { intervention is suitable and effective for } \\
\text { most child with ADHD }\end{array}$ & & & & & & & 30.213 & $0.001 *$ \\
\hline Low & 10 & 20.0 & 2 & 4.0 & 2 & 4.0 & & \\
\hline Moderate & 24 & 48.0 & 17 & 34.0 & 4 & 8.0 & & \\
\hline High & 16 & 32.0 & 31 & 62.0 & 44 & 88.0 & & \\
\hline
\end{tabular}

*Significant

Table (4): Distribution of studied teachers in relation to their practice experience in providing organization at classroom ( $\mathrm{n}=50)$

\begin{tabular}{|c|c|c|c|c|c|}
\hline Variables & Before & $\begin{array}{c}\text { Immediately } \\
\text { after }\end{array}$ & After one month & $X^{2}$ & $\mathrm{P}$ \\
\hline
\end{tabular}




\begin{tabular}{|c|c|c|c|c|c|c|c|c|}
\hline & No & $\%$ & No & $\%$ & No & $\%$ & & \\
\hline $\begin{array}{l}\text { How much knowledge/ understanding do } \\
\text { you have regarding this intervention }\end{array}$ & & & & & & & 17.538 & $0.001 *$ \\
\hline Low & 8 & 16.0 & 1 & 2.0 & 1 & 2.0 & & \\
\hline Moderate & 12 & 24.0 & 3 & 6.0 & 6 & 12.0 & & \\
\hline High & 30 & 60.0 & 46 & 92.0 & 43 & 86.0 & & \\
\hline $\begin{array}{l}\text { How skilled do you perceive yourself to } \\
\text { be in implementing this intervention? }\end{array}$ & & & & & & & 24.257 & $0.001 *$ \\
\hline Low & 7 & 14.0 & 0 & 0.0 & 1 & 2.0 & & \\
\hline Moderate & 18 & 36.0 & 4 & 8.0 & 7 & 14.0 & & \\
\hline High & 25 & 50.0 & 46 & 92.0 & 42 & 84.0 & & \\
\hline $\begin{array}{l}\text { To what degree do you think this } \\
\text { intervention is suitable and effective for } \\
\text { most child with ADHD }\end{array}$ & & & & & & & 8.205 & $0.017 *$ \\
\hline Low & 7 & 14.0 & 0 & 0.0 & 1 & 2.0 & & \\
\hline Moderate & 12 & 24.0 & 11 & 22.0 & 6 & 12.0 & & \\
\hline High & 31 & 62.0 & 39 & 78.0 & 43 & 86.0 & & \\
\hline
\end{tabular}

*Significant

Table (5): Distribution of studied teachers in relation to their practice experience in time out from positive reinforcement $(\mathrm{n}=50)$

\begin{tabular}{|c|c|c|c|c|c|c|c|c|}
\hline \multirow{2}{*}{ Variables } & \multicolumn{2}{|c|}{ Before } & \multicolumn{2}{|c|}{$\begin{array}{c}\text { Immediately } \\
\text { after }\end{array}$} & \multicolumn{2}{|c|}{ After one month } & \multirow{2}{*}{$X^{2}$} & \multirow{2}{*}{$\mathrm{P}$} \\
\hline & No & $\%$ & & $\%$ & No & $\%$ & & \\
\hline $\begin{array}{l}\text { How much knowledge/ understanding do } \\
\text { you have regarding this intervention }\end{array}$ & & & & & & & 28.114 & $0.001 *$ \\
\hline
\end{tabular}




\begin{tabular}{|c|c|c|c|c|c|c|c|c|}
\hline Moderate & 13 & 26.0 & 14 & 28.0 & 11 & 22.0 & & \\
\hline High & 17 & 34.0 & 34 & 68.0 & 36 & 72.0 & & \\
\hline $\begin{array}{l}\text { How skilled do you perceive yourself to } \\
\text { be in implementing this intervention? }\end{array}$ & & & & & & & 34.032 & $0.001 *$ \\
\hline Low & 17 & 34.0 & 2 & 4.0 & 2 & 4.0 & & \\
\hline Moderate & 18 & 36.0 & 9 & 18.0 & 11 & 22.0 & & \\
\hline High & 15 & 30.0 & 39 & 78.0 & 37 & 74.0 & & \\
\hline $\begin{array}{l}\text { To what degree do you think this } \\
\text { intervention is suitable and effective for } \\
\text { most child with ADHD }\end{array}$ & & & & & & & 35.317 & $0.001 *$ \\
\hline Low & 16 & 32.0 & 4 & 8.0 & 2 & 4.0 & & \\
\hline Moderate & 22 & 44.0 & 15 & 30.0 & 8 & 16.0 & & \\
\hline High & 12 & 24.0 & 31 & 62.0 & 40 & 80.0 & & \\
\hline
\end{tabular}

*Significant 
Table (6): Correlation between total knowledge and experience score in relation to age in years

\begin{tabular}{|c|c|c|}
\hline \multirow{2}{*}{ Total score } & $\mathrm{2}$ & Age in years \\
\cline { 2 - 3 } & -0.362 & $\mathrm{P}$ \\
\hline Knowledge & 0.295 & $0.011^{*}$ \\
\hline $\begin{array}{c}\text { Practices } \\
\text { experience }\end{array}$ & & $0.044^{*}$ \\
\hline
\end{tabular}

*Significant at $p<0.05$

Table (7): Correlation between knowledge and experience total scores

\begin{tabular}{|c|c|c|}
\hline \multirow{2}{*}{ Total score } & \multicolumn{2}{|c|}{ Knowledge and Experience total score } \\
\cline { 2 - 3 } & $\mathrm{r}$ & $\mathrm{P}$ \\
\hline Before & 0.191 & 0.183 \\
\hline Immediately after & 0.362 & $0.001^{*}$ \\
\hline After one month & 0.423 & $0.002^{*}$ \\
\hline
\end{tabular}

Figure (1): Distribution of studied teachers in relation to total knowledge score in dealing with children with attentive hyperactivity disorder

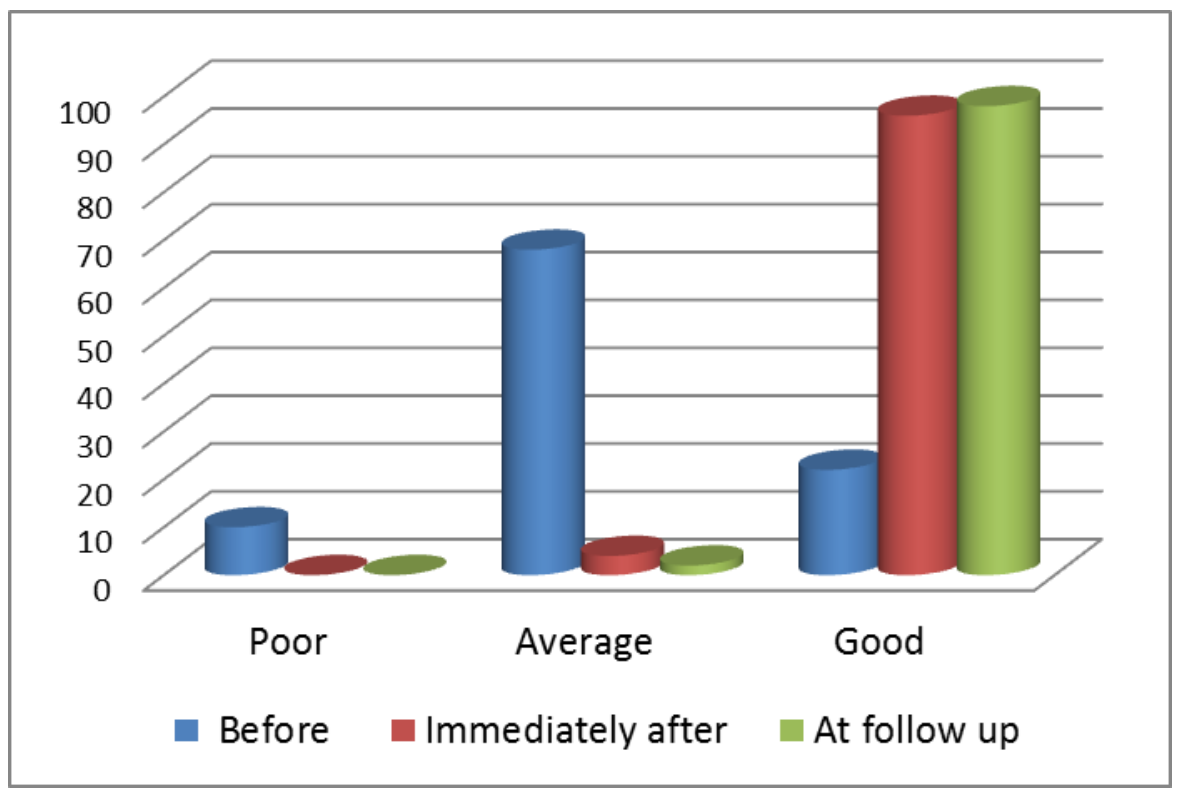

Figure (2): Distribution of studied teachers in relation to total experience score in dealing with children with attentive hyperactivity disorder 


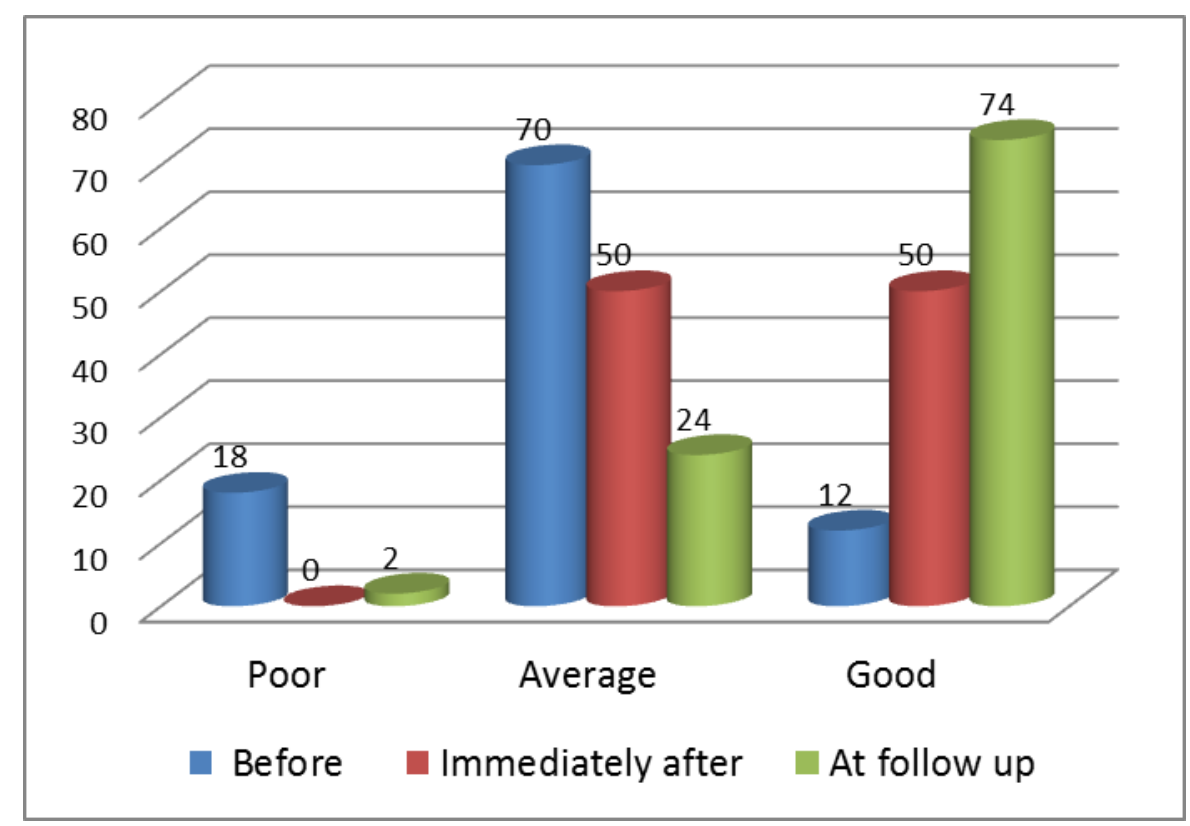

Figure (3): Relation between total knowledge score and Residence

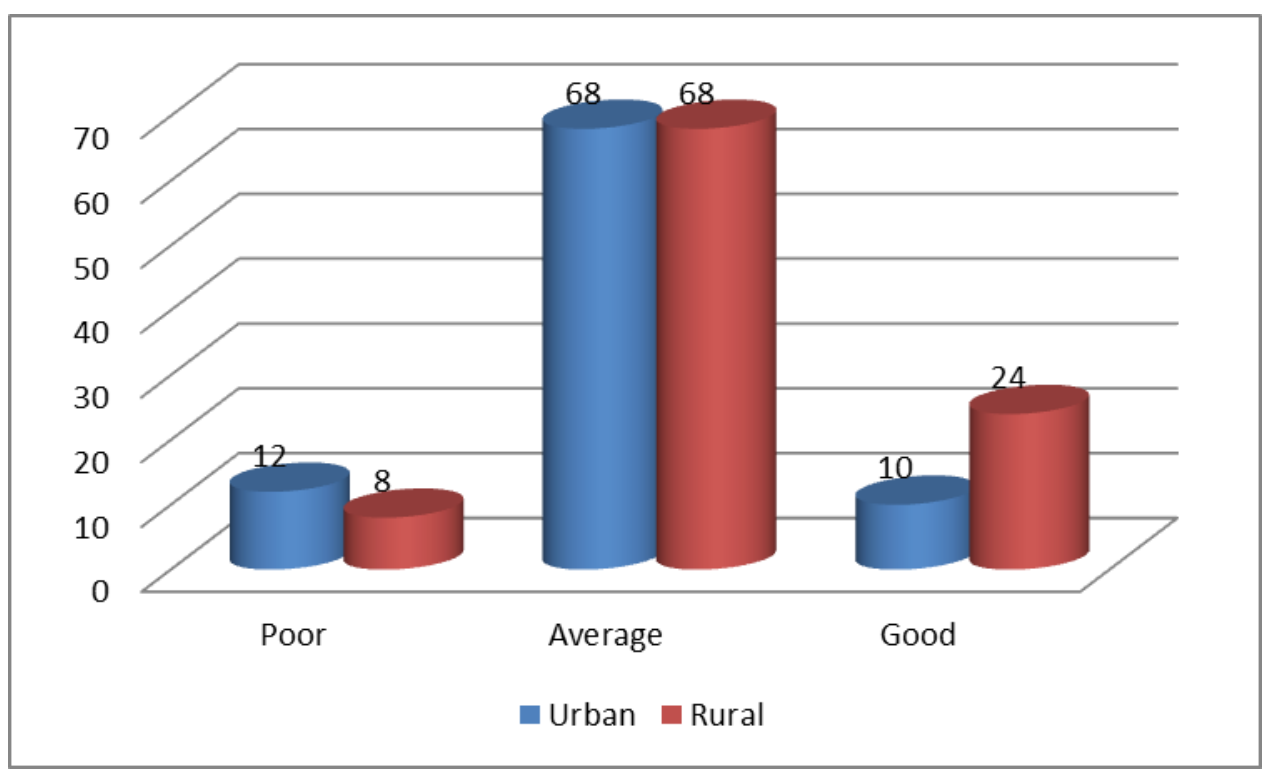

Figure (4): Relation between total practice experience score and residence 


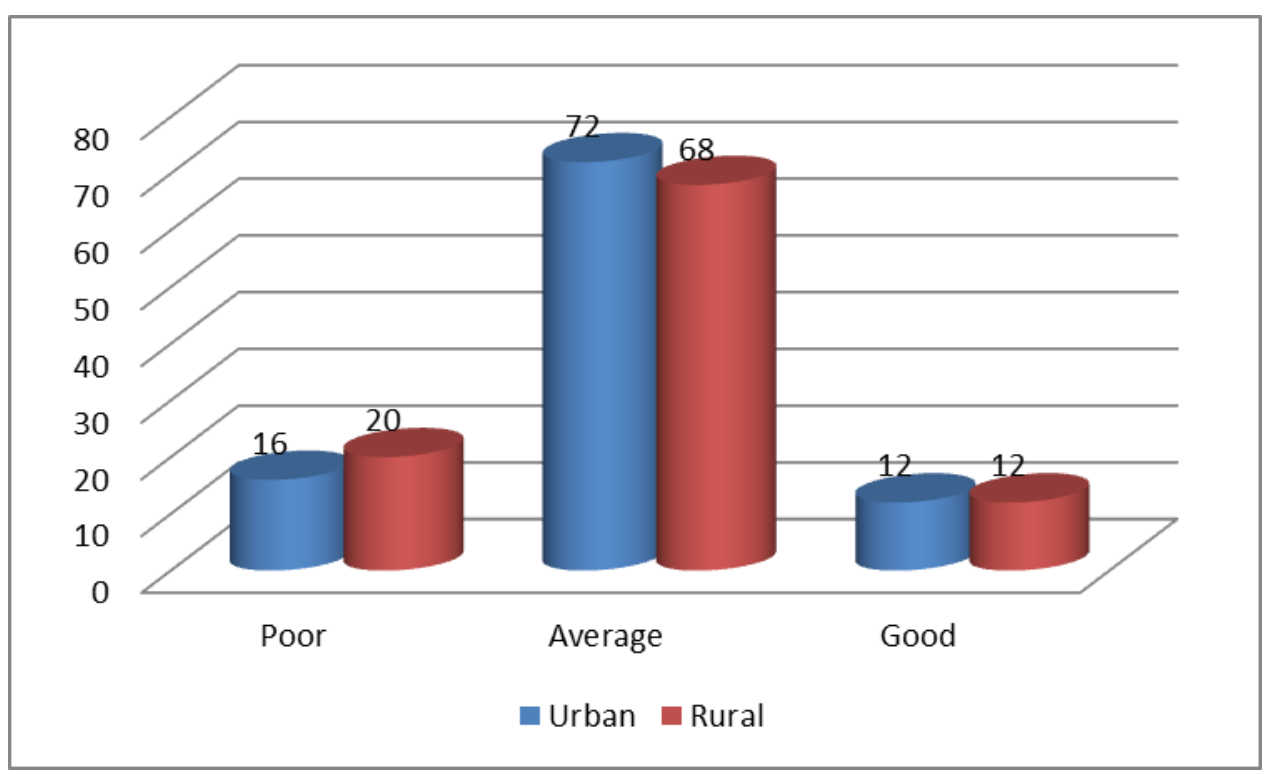

Discussion;

Attention Deficit Hyperactivity Disorder is one of the most prevalent childhood and adolescent behavioral disorders affecting children worldwide. It is estimated that it found in three to five percent of the school-age population. This disorder causes grave problems for children, teachers, family and siblings. This research determine the teacher's knowledge, attitudes and behaviors towards the children with ADHD, and giving them inservice educational programs to provide teachers with knowledge and skills that are necessary to manage challenging classroom behaviors and improve academic and social/ emotional outcomes ${ }^{(20-24)}$. So the aim of this study is to evaluate the effect of an educational program about Attention Deficit Hyper Activity Disorder on primary schools teachers' knowledge and skills.

Regarding the personal characteristics of the studied teachers, the study result revealed that more than half of the studied teachers had more than 31 years old, This result may be due to that there aren't any chance of appointment by the government for a new jobs except by contract so that more than half of teachers are old generations. This supported by the Bussing et al., (2002) ${ }^{(25)}$ \& Barnet T, Corkum O, \& Elik L, 2012 $2^{(26)}$ in their study of general education for primary school teachers about Attention-deficit/hyperactivity disorder that aimed to increase teacher knowledge and experience regard ADHD, This revealed that $54 \%$ of the teachers were $30-50$ years old.

On the other hand, Piccol O, Torsky J \&Waishwell L $(2007)^{(27)}$ in their study of primary school teachers knowledge and misperception regarding ADHD that aimed to recognize knowledge of primary school teachers about ADHD which disagreed with this study as they revealed that $65 \%$ of primary school teachers were younger than 33years old. Regarding years of teaching experience, the present study result showed that nearly half of teachers had work experience about 25-30 years. This result may be due to the same previous reasons in these days that there isn't any chance of appointment by the government for a new job except by contracts so that nearly half of teachers are old generation.

This result is similar to Bussing et al, (2002) ${ }^{(25)}$ that revealed that half of teachers had work experience from 24-30 years. But this study is not similar to the Sciqutto M ,Terjesen $M^{(28)}$ in their study of the knowledge and attitude of primary school teachers towards childhood attention deficit hyperactivity disorder that aimed to recognize knowledge of 
primary school teachers about ADHD. It revealed that the average number of years of teaching experience was between 12-14 years. Regarding the Post graduate educational training the present study result showed that majority of the studied teachers had post graduate educational training, this result may be due to that now in all schools there are mandatory training for all teachers, as there are training units and responsible teachers for it and these teachers must make at least one training course in areas according to the teachers' needs by borrowing lecturers or trainers from outside school. This result was similar to Salend S \& Rohena E, $2003^{(29)}$ who mentioned that $77 \%$ of the studied teachers had post graduate educational training.

In the same direction Sciqutto $M$, Terjesen $M{ }^{(28)} \&$ Bender H, Frank $A^{(30)}$ who were congruent with the present study as they revealed that $80 \%$ of the studied teachers had post graduate educational training. But on the other hand, Schlozman S ,Schlozman R , $2000^{(31)} \&$ Bender H, Frank $A^{(30)}$ who disagreed with this study as they revealed that $70 \%$ of the studied teacher's hadn't post graduate educational training.

Regarding the total knowledge score, the present study represented an improvement in the total knowledge level immediately after and after the implementation of the educational program compared with before the implementation of the educational program. This result may be probably due to the immediate effect of educational program session which was supported by booklets about ADHD while one month after the implementation of the educational program this improvement decreased but it was still significant which may de probably due to the absence of continuing training and education in this area, and work overloads. This result agreed with Barnet T, Corkum O \& Elik L ,2012 (26) who revealed that there are improvements in the teacher's total knowledge score. On the other hand, this result disagreed with Stern H, Garg A\& Stern P, 2007 ${ }^{(32)}$ in their study as it represented that the majority of the teachers have a low level of knowledge regarding ADHD.

Regarding the total experience score, the present study represented an improvement in the total experience score immediately after and after one month of the implementation of the educational program compared with before the implementation of the educational program. This result may be probably due to the immediate effect of educational program session which was supported by booklets about ADHD .While one month after the implementation of the educational program, this improvement decreased but it was still significant .This may be probably due to the absence of continuing training and education, and work overload.

This result was in agreement with Pisecco S ,Hamilton R, (2006) ${ }^{(33)}$ who revealed that majority of the studied teachers have good experience regarding ADHD intervention. On the other hand Schlozman S ,Schlozman R ,2000 ${ }^{(31)}$ who disagreed with this study as they revealed that the majority of the studied teachers have poor experience regarding ADHD intervention. Regarding teachers' experience about giving students verbal and non verbal, positive and negative reinforcement, the present study represented that the majority of the teachers have good knowledge, experience and positive attitudes towards this intervention after the implementation of the educational program. This result may be probably due to the effective educational program sessions which gave the teachers the necessary and right knowledge about ADHD management. This result agreed with Ghanizadeh A et al.,2006 ${ }^{(34)}$, Perold M et al., $2010^{(35)} \&$ Rodrigo $\mathrm{M}$ et al., $2011^{(36)}$ who revealed that $85 \%$ of the studied the teachers have good knowledge, experience towards this intervention.

Regarding the teacher experience about response cost intervention, the present study represented that majority of the teachers have good knowledge, experience and positive 
attitudes towards this intervention after the implementation of the educational program. This may be probably due to the presence of technological facilities in the work place such as computers and libraries that effectively facilitate the implementation the educational program. This result was in agree with Curtis D, Pisecco S \& Hamilton R, $2006{ }^{(37)}$ who revealed that $80 \%$ of studied teachers were knowledgeable with response cost intervention.

Regarding the teachers' experience about providing organization at classrooms, the present study represented that the majority of the teachers have good knowledge, experience and positive attitudes towards this intervention after the implementation of the educational program. This result may be probably due to that majority of the studied teachers were highly educated and have desire for change practice, this study was similar to Baughman, K, $2006^{(38)}$ \& Stolzer K, $2009^{(39)}$ who revealed that there are improvements in teachers knowledge and experience regarding this intervention.

Regarding the teachers experience about time out from positive reinforcement, the present study represented that majority of the teachers have good knowledge, experience and positive attitudes toward this intervention after implementation of the educational program. This result may be probably due to the effective educational program sessions which gave the teachers the necessary and right knowledge about ADHD management. This result was in agreement with Hawkins J, et al. ,(2006) ${ }^{(40)}$ in their study who represented that $65 \%$ of the studied teachers have good knowledge about how to use the intervention that called time out from positive reinforcement. In the same direction ,Bekle M, 2004 ${ }^{(41)}$ \& Curtis D et al., 2006 ${ }^{(37)}$,their study agreed with the study as they revealed that $83 \%$ of studied teachers have good knowledge about how to use the intervention that called time out from positive environment.

The present study represented that there is no relationship between the total knowledge, experience score and residence. This result may be probably due to that on these recent days new technology and E-learning become available in all places, all teachers either from urban places or rural areas log on to web sites and onto the external worlds at any time and at any places easily. This result not similar to Boylan C\& Bandy H, $2003^{(42)}$, in their study of assessing the effect of residence on the teachers' knowledge and experience regarding ADHD. Who revealed that residence affects on teachers on their knowledge and experience as teachers in urban places have more knowledge than other teachers in rural areas. But with the researcher's respect to this study and its opinion, this study was implemented in 1994, and there are large differences between 1994 and 2015 in all things; especially, in technology and its related topics.

On the other hand, West J, et al., $2005^{(21),}$ were congruent with this study as they revealed that there is no relationship between the total knowledge, experience score and residence. But Timimi N \& Taylor D, 2004 ${ }^{(43)}$ in their study agreed with the present study, as they revealed that there is no relationship between the total knowledge, experience score and residence.

The present study results revealed that there is a statistically significant relationship between the total knowledge and experience score in relation to the age in years. This result may be probably due to that the new generations of teachers are recently graduated and they still have some knowledge from their educational courses that may contain knowledge about ADHD, but they haven't experience as older generations. While the older generations of teachers became more satisfied with the traditional knowledge and had no the capacity to deal with the new concepts but at the same time they have experience more

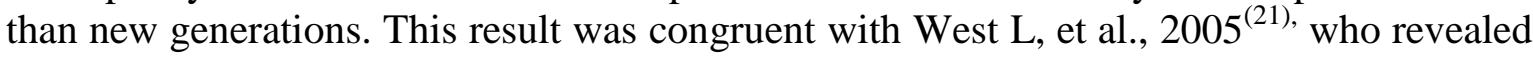
that older generations of teachers are less knowledgeable and more experienced than new generation of teachers. 
Also Aguiar et al., 2014 ${ }^{(44)}$, Barnet T, Corkum O \& Elik L ,2012 ${ }^{(26)}$ in their study agreed with the present study as it revealed that new generation of teacher is more knowledgeable and less experienced than old generation of teachers. On the other hands Baughman K, $2006^{(38)}$, Stolzer K, $2009^{(39)}$ who disagreed with the present study as it reported that the new generations of teachers are less knowledgeable and more experienced than older generations.

\section{Conclusion}

Based on the results of the present study, The Findings confirmed the important role of teacher in management of children who have Attention Deficit Hyper Activity Disorder, and also confirmed the effect of the educational program on enhancing teacher's knowledge and experience regarding ADHD. It can be concluded that the majority of studied teachers had a high level of knowledge and experience that enable them to deal with student who has ADHD after the implementation of this educational program. Total score of knowledge and experience of teachers regarding ADHD before intervention was significantly different from immediately after, and at follow up.

\section{Recommendations}

Recommendations related to teachers:

-Teachers should be offered in-service training program in ADHD, as well as behavioral management and academic interventions (curriculum adaptations) regarding ADHD.

-In-service training for teachers should be supplemented with ongoing consultation or support (collaboration with educational psychologists)..

Recommendations related to parents.

-Teachers should be encouraged to involve the parents in the learning process for their children.

-Parent training should focus on promoting social and self- regulating behavior, managing disruptive child behavior at home and reducing parent-child conflict.

Recommendations related to future researches.

-There should be an investigation about the relationship between teachers' behaviors and school policies, resources, to gain a better understanding of the impact of ADHD across our educational system.

\section{Reference}

1-Mohr W. Psychiatric Mental Health Nursing. $7^{\text {th }}$ ed., Philadelphia: Lippincott. 2009; 89 90.

2-Biederman, J. High Risk for Attention Deficit Hyperactivity Disorder and its onset. American Journal of Psychiatry., 2007; 152(3):431-435.

3-Richters E, Arnold L, Jensen S. Collaborative Multimodal Treatment Study of children with ADHD. The American Academy of Child and Adolescent Psychiatry journal., 2000; 34: $987-90$

4-Vidbeck S. Psychiatric Mental Health Nursing. $6^{\text {th }}$ ed.,USA:Lippincott Williams;2014;431.

5-Jawaid A, Zafar M, Naveed A, Sheikh S, Waheed S, Zafar A.et al. Knowledge of primary pediatric Care providers regarding Attention Deficit Hyperactivity Disorder. Singapore Medical Journal, 2008;33: 980-85. 
6-Halpern M , Healey M. The Influences of Environ-mental, Cognitive Enhancement, and physical exercise on brain development of ADHD child Neuroscience Journal, 2011; 35(3):621-34.

7-Farone S, Mick E. Molecular Genetics of Attention Deficit Hyperactivity Disorder. Neuroscience Journal, 2010; 33(1).121-23.

8-Snider V, Busch T, Arrowroot L. Teacher knowledge Of Stimulant Medication And ADHD. Neuroscience Journal,2003; 24: 46-50.

9-DuPaul G, Eckert T. Interventions for students with Attention-Deficit/Hyperactivity Disorder. School Psychology Review, 2008 ;26 (3): 369-82.

10- Power T, Hess L, Bennett D. The acceptability of Interventions for Attention-Deficit Hyperactivity Disorder among elementary school Teachers. Developmental Pediatric Nursing Journal, 2005; 16(4): 238-43.

11-Elliott, S. Acceptability of behavioral treatments; Review of variables that influence treatment selection.2004;19 (1):668-80.

12-Ghanizadeh A, Bahredar M, Moeini S. Knowledge and Attitudes towards Aattention Deficit Hyperactivity Disorder among elementary school teachers. Psychiatric nursing Journal, 2006; 34:60-8.

13-Cormier E. Attention Deficit Hyperactivity Disorder. Pediatric Nursing Journal, 2008; 23(5):345-57.

14-Barkley R. Attention-Deficit Hyperactivity Disorder A handbook for diagnosis and treatment. 2nd Ed., New York: The Guilford Press; 2001; 66-9

15-Reid R, Vasa S, Wright G. An Analysis of Teachers' perceptions of Attention DeficitHyperactivity Disorder. Research and Development Journal,1999; 27(3):195-202.

16-Reimers T M, Wacker D, Koeppl G. Acceptability Of Behavioral Interventions. School Psychology Review, 2004; 16 (2): 212-27.

17- Ferri N .Clinical Advisor.2nd Ed, St Louis: An Imprint of Elsevier;2013;67-99.

18-Garque N, Tarraga L, Miranda L .Teachers'knowledge and Attitudes Regarding Attention Deficit Disorder. ERS Spectrum Journal, 2007; 16(1):36-44.

19- Matloc L .Teacher Intervention Survey for ADHD .ERS Spectrum j,1999;7 (2) ;26-27

20- Syed E, Hussein S. Increase in teachers' knowledge about ADHD after a weeklong training program: A pilot study. Journal of Attention Disorders 2010; 13(4): 420-403.

21- West L,Taylor M, Houghton S\&Hudyma S.A comparison of teachers' and parents' knowledge and beliefs about ADHD. School Psychology International 2005;26 (4): 192208.

22-Michael H, PeterT, James F.Current Diagnosis and Treatment. $2^{\text {nd }}$ ed ,Singapore: Micgraw hill Co.,2008:639-642.

23-Youssef F, Bachew R, Bodie D, Leach R.Knowledge and attitudes towards mental illness among college students: Insights into the wider English- speaking Caribbean population. International Journal of Social Psychiatry,2014;60(1):47-54. 
24-DuPaul G, Stoner G.ADHD InThe Schools. Assessment and Intervention Strategies.3 ${ }^{\mathrm{rd}}$ Ed. New York: Guilford Press Co.,2003;244.

25-Bussing R, Gary F, Leon C, Garvan W, \& Reid R. General classroom teachers' information and perceptions of attention deficit hyperactivity disorder. Attention disorder Journal (2002);27 (4): 327-39.

26-Barnet T, Corkum O \& Elik L.Behavioral interventions used in ADHD. Psychological Journal 2012;20 (2): 10-17.

27-Piccol O, Torsk J \&Waishwell L. Teachers' knowledge and attitudes regarding Attention Deficit Disorder. ERS Spectrum, 2007; 16(1): 36-40.

28-Sciutto M, Terjesen M, Bender Frank A. Teachers' Knowledge andMis perceptions of Attention-Deficit/Hyperactivity Disorder. Psychology in the Schools 2004; 37 (2):115-22.

29- Salend S \&Rohena E. Students with Attention Deficit Disorder. Psychiatric medical Journal, 2003; 38 (5):259-69

30- Bender H, Frank L. Attention Deficit Disorder. Psychiatric Medical Journal, 2004; 37 (1): 59-69

31- Schlozman S \&Schlozman R. Classroom ADHD. Educational Journal 2000; 34 (3):204-9

32- Stern H,Garg A \& Stern P. When Children With Attention- Deficit /Hyperactivity Disorder Become Adults. Southern Medical Journal; 200795 (9):985-92.

33-Pisecco S \& Hamilton R.Teachers' knowledge and attitudes regarding Attention Deficit Disorder.Psychiatric Australian Journal 2006; 33(9): 217-20

34-Ghanizadeh A, Bahredar M,MoeiniS. Knowledge and attitudes towards attention deficit hyperactivity disorder among elementary school teachers. Patient Education \& Counseling 2006; 63 (7):84-88.

35- Perold M, Louw C, KleynhansS.Primary school teachers' knowledge and misperceptions of attention deficit hyperactivity disorder (ADHD). South African Journal of Education; $2010: 44$ (30) 457-73.

36- Rodrigo M, Perera D, ErangaV, Williams S. KuruppuarachchiK.The knowledge and attitude of primary school teachers in Sri Lanka towards childhood attention deficit hyperactivity disorder. Ceylon Medical Journal; 2011: 56(8) 51-4.

37-Curtis D, Pisecco S \& Hamilton R. Teacher perceptions of classroom interventions for children with ADHD. School Psychology Quarterly 2006 :42(21):171- 96.

38-Baughman K. Teacher perceptions of classroom interventions for children with ADHD Attention Deficit Journal 2006: 32 (11):151- 66.

39-Stolzer K. The knowledge and attitude of primary school teachers. School Psychology Quarterly 2009: 42(21):181-96.

40-Hawkins, J, Martin S, Blanchard K. Brady M. Teacher perceptions of classroom interventions for children with ADHD. School Psychology Journal 2006 :32(1):161- 86.

41-Bekle M. Attention-Deficit/Hyperactivity Disorder (ADHD). Medical Psychiatric Journal 2004: 43(9): 227-30. 
42-Boylan C \& Bandy H. Education and training for rural and urban teachers, and Issues affecting rural communities. Pennsylvania State University Press; 2003: 8,(1) : 55-68.

43-Timimi N\& Taylor D.Treatment of attention- deficit-hyperactivity disorder. New England Journal of Medicine 2004; 34(2):770-80

44-Aguiar A, Kieling R, Costa A, Chardosim N, Dorneles B, Almeida M, Rohde L. Increasing teachers' knowledge about ADHD and learning disorders. Journal of Attention Disorder; 2014: 18(41): 691-98. 